\title{
Letter
}

\section{Wildlife migration in Ethiopia and South Sudan longer than 'the longest in Africa': a response to Naidoo et al.}

Naidoo et al. (2016) reported a $500 \mathrm{~km}$ round-trip zebra Equus quagga migration as A newly discovered wildlife migration in Namibia and Botswana is the longest in Africa. Their paper is interesting but their claim is incorrect, as demonstrated by the evidence presented here of a substantially longer terrestrial mammalian migration.

One of the most spectacular but least studied mass migrations in Africa is that of the white-eared kob Kobus kob leucotis across the Boma-Gambela ecosystem, which straddles the boundary of Ethiopia and South Sudan. This migration was first described in a documentary by R. and J. Kemp in 1980 for Anglia TV, UK, in the Survival series, and again featured in a documentary in 2013 (The WaterChannel, 2013). The website of National Geographic mentions that the kob population numbers 800,000 and migrates $>1,500$ $\mathrm{km}$, but no source is provided (Anon., 2016).

Several aspects of the migration of the white-eared kob were previously known. Marjan (2014) reviewed available literature and carried out aerial surveys, and estimated a population size of 792,782; he also tracked two collared individuals, recording a migration of $>895 \mathrm{~km}$. In 2013 tracking of white-eared kob with satellite collars showed the key important habitats for the species across the BomaGambela ecosystem (G.G. Rolkier, pers. obs.).

As part of an ongoing research programme we fitted satellite collars to 63 white-eared kob (43 in 2013 and 20 in 2015). Our preliminary results indicate that one individual migrated a round-trip distance of $825 \mathrm{~km}$ (Fig. 1), which may be taken as a proxy for the migration of several large herds. Future research will provide more detailed data and investigate variations between years and between individuals, and the ecological and anthropogenic factors influencing this migration. Over time we expect to describe a migration of c. $900 \mathrm{~km}$, possibly the longest terrestrial mammalian migration on record.

There has been armed conflict throughout the study area for many years. This is a serious constraint on conservation efforts and explains why the migration remains poorly known. Despite security and logistical challenges we hope to be able to contribute to the understanding and conservation of this unique migration.

Pablo Schapira and Marina Monica African Parks Network, Gambela, Ethiopia

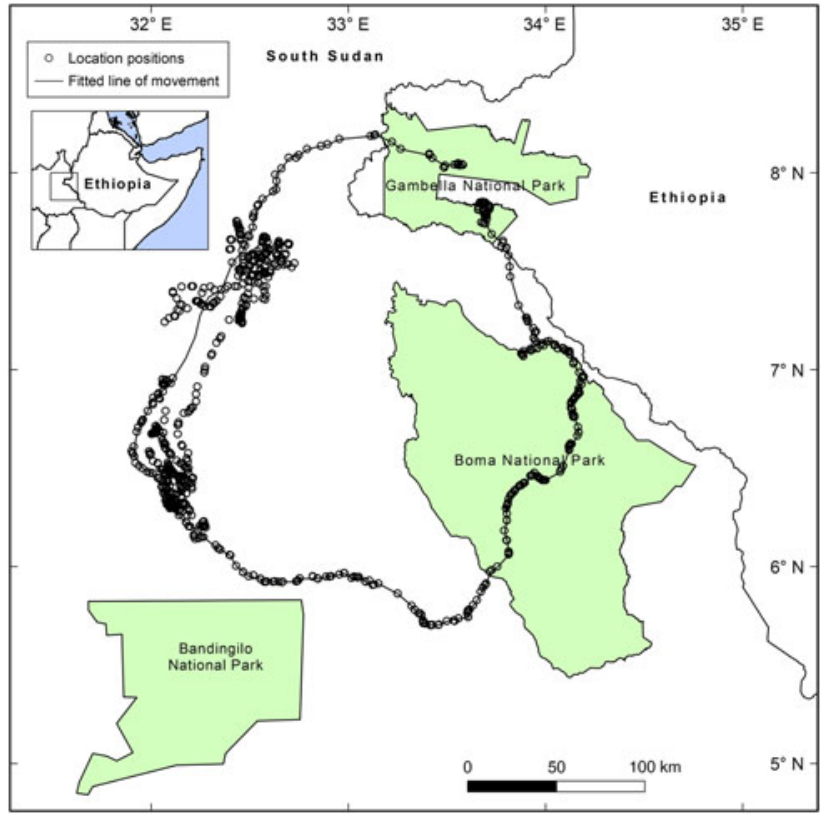

FIG. 1 Migration of an adult male white-eared kob Kobus kob leucotis in the Gambela-Boma transboundary ecosystem. The line fitted through the location positions approximates the straight line distance, which is $825 \mathrm{~km}$.

Gatluak Gatкотн Rolkier Ethiopian Wildife Conservation Authority, Gambela National Park, Gambela, Ethiopia

HaNS BAUER WildCRU, Recanati Kaplan Centre, University of Oxford, Tubney, OX13 5QL, UK

E-mail hans.bauer@zoo.ox.ac.uk

\section{References}

Anon. (2016) White-eared kob. Http://animals.nationalgeographic. com/animals/mammals/white-eared-kob/ [accessed 17 March 2016].

MarJan, M.D. (2014) Movements and conservation of the migratory white-eared kob (Kobus kob leucotis) in South Sudan. PhD thesis University of Massachusetts, Amherst, USA. Http://scholarworks. umass.edu/cgi/viewcontent.cgi? article $=1216 \&$ context $=$ dissertations_2 [accessed 27 April 2016].

Naidoo, R., Chase, M.J., Beytell, P., Du Preez, P., Landen, K., Stuart-Hill, G. \& TAYloR, R. (2016) A newly discovered wildlife migration in Namibia and Botswana is the longest in Africa. Oryx, $50,138-146$.

The Water Channel (2013) Gambella's Hidden Treasure. Http:// www.thewaterchannel.tv/media-gallery/830-gambella-s-hiddentreasure [accessed 25 April 2016]. 